\title{
A UNIFICAÇÃO DO DIREITO E A PAZ SOCIAL
}

\author{
O. Martins Gomes \\ Catedrático de Direito Internacional Pri- \\ vado da Faculdade de Direito da Univer- \\ sidade do Paraná \\ (Tese apresentada ao Congresso \\ pela Fraternidade Universal, reali- \\ zado em Curitiba, em março dêste \\ ano.
}

Instala-se agora em Curitiba o Terceiro Congresso Internacional pela Fraternidade Universal, sob os auspícios do Instituto Neo-Pitagórico. A escolha da cidade para a magna realização está bem justificada, por ser a sede da frateria dos neo-pitagóricos, instituída, há mais de cinqüenta anos, por Dario Vellozo, e destinada ao estudo e ao altruismo, para culto da verdade, da justiça, da liberdade, da paz, da fraternidade e da harmonia, não reconhecendo qualquer distinção por motivo de raça, nacionalidade, fortuna, posição social, credo religioso, filosófico ou político.

Dario Vellozo, apóstolo do bem, prpofessor, primoroso orador, escritor e poeta, predisse que o "ciclo do Brasil é de trabalho e paz; subir do utilitário aos grandes ideais; da paz universal ser o semeador; da terra universal ser o doutrinador".
O temário do atual Congresso consiste em indicar os meios práticos para efetivação da paz social, diretos, indiretos, imediatos e mediatos.

O professor universitário Rosala Garzuze, atual Presidente do Instituto Neo-Pitagórico, por nomeação e sucessão de seu eminente fundador, apela para os homens de estudo, para os juristas, para todos os interessados nos problemas humanos da paz, no Paraná, a fim de que dêem sua contribuição espiritual ao Congresso.

Antigo membro, que fui, daquela nobre agremiação, como aluno, admirador e amigo de Dario Vellozo, sinto-me capacitado a prestar minha modesta colaboração à altruística assembléia, na qualidade de professor de direito internacional privado. O âmbito desta ajuda não permite ater-me ao código 
de moral individual contido nos Versos de Ouro de Pitágoras. Mas, abrigado à sombra da mesma Árvore de Samos, embora na dúbia e frágil atitude humana para preferir o ramo indicador da vereda estreita da renúncia, desvendadora do arcano eterno, encontro também, nas minhas lucubrações de ordem didática, meios práticos, indiretos e mediatos, para consecução da paz social.

As diferenças de meio geográfico, de raças, de línguas, de origem, de formação histórica, de crenças, de idéias morais, de cultura, de civilização, dividiram os povos da terra. E cada nação constituída em estado organizou o estatuto regulador de suas condições existenciais, que são as suas leis. Mas, por motivo das discriminações já enunciadas, ou mesmo, apesar de, muitas vêzes, coincidirem fatores semelhantes, as tendências populares conduzem a concepções diferentes sôbre os modos de viver, mormente na órbita das relações de família. Daí a disparidade de sistemas legislativos, enunciada e justificada por Montesquieu, ao mostrar que cada povo deve ter leis bem apropriadas a êle.

$\mathrm{E}$, como os homens não mantêm sua vida permanentemente adstrita às mesmas circunstâncias de natureza político-jurídica, dentro da mesma circunscrição territorial, mas, ao contrário, viajam dum país para outro, participam de múltiplos intercâmbios, ainda mais em face das atuais facilidades de transporte por meio da aviação, apresentam-se, em conseqüência, dificuldades freqüentes para solução das relações de ordem privada entre êles.
Início e fim da personalidade, estado, capacidade geral ou especial, impedimentos matrimoniais e formas de celebração, regimen de bens do casal, sucessão, modos de aquisição de bens, casamento consular, nulidade do matrimônio, divórcio, separação de corpos, qualificação e regência de bens e obrigações, vocação hereditária, capacidade sucessória, ordem pública, - eis alguns dos aspectos onde ocorrem habitualmente conflitos entre as leis de diferentes países.

Daí possuir cada Estado, na sua legislação, um conjunto de normas solucionadoras da divergência. A norma apontará, quando se apresenta um elemento estrangeiro ou assemelhado, em face de outros fatores vinculados a outro ou outros países, qual a lei, e de que país, deve ser aplicada, para dirimir a questão no seu conteúdo material.

Tais preceitos formais, indicativos da legislação competente, pertencem ao direito interno de cada país, constituindo um super-direito. Pode suceder que, por sua vez, divirjam também êles entre si, dando lugar então a outros conflitos, chamados do segundo grau, de mais difícil solução. E ocorrem mais freqüentemente em razão da discrepância fundamental no critério informador do estatuto pessoal, para regular direitos de família, de sucessão e mesmo de propriedade, adotando para tal, muitas legislações, como a do Brasil, a lei do país em que a pessoa fixou seu domicílio, e outras, como a da Itália, a lei nacional da pessoa.

A verdade é que o princípio da territorialidade da lei, segundo o qual, dentro do país, se aplica ùni- 
camente sua legislação, com exclusão de qualquer outra, não atende ao espírito de justiça e também de eqüidade, em virtude do qual, conforme as circunstâncias, deve aplicar-se ao caso em exame a legislação estrangeira.

Ao da territorialidade se opõe, portanto, em tais situações, o princípio da extraterritorialidade da lei. Não, como se tem ainda hoje admitido, por uma cortesia internacional (commitas gentium), ou pelo interêsse da reciprocidade, quer diplomática quer legislativa, ou pelo fundamento só da nacionalidade, como preconizou Mancini. Invoca-se modernamente, como razão de ser, a doutrina enunciada, há cêrca de um século, por Savigny, - da comunidade do direito entre os povos de igual grau de civilização, examinando-se em cada relação jurídica, onde surge o conflito, o ponto de conexão com a lei aplicável, que pode ser estrangeira.

Essa concepção de comunidade ou comunhão do direito, já por si, conduz à idéia de universalidade, de fraternidade humana. $E$ nesse rumo juristas filósofos, como Pillet na França e Clovis Bevilaqua e Rodrigo Octavio no Brasil, conceberam a existência duma sociedade internacional dos indivíduos de nacionalidades diferentes e que entram em relações fora do âmbito jurídico de seus países, achando esta concepção mais expressiva do que a de comunhão de direito, de Savigny.

Procura-se o remédio para a disparidade das leis. A prescrição mais eficiente seria, sem dúvida, a unificação do direito, para maior aproximação dos povos, reforçan- do os elos da fraternidade e melhor propiciando a paz social. A unidade legislativa consistiria, por exemplo, em adotarem os países, pelo menos aquêles que mais se aproximam no parentesco - mesma origem histórica ou mesma cultura, como queria Demogue - o mesmo código civil. Si a sugestão esbarra na utopia, ainda mais nos institutos referentes à família, tornando inconciliáveis os pontos de vista diferentes, tem-se, entretanto, conseguido já essa unidade em setores da atividade humana de feição mais abstrata, objetivando a esfera dos negócios, menos influenciáveis pelas idéias morais.

Há, de exemplos, as leis uniformes sôbre letra de câmbio, nota promissoria e cheque, votadas em 1912 da Conferência de Haia e em 1930 na Conferência de Genebra, esta sob a égide da Sociedade das Nações.

Mesmo nesses ramos, como em outros, ligados ao direito comercial, não se tem conseguido uma unificação completa, pois, ante dissídios inevitáveis, permite-se a liberdade legislativa nos assuntos divergentes. Mas, objetivando ainda a harmonia, quanto possível, assinam as altas partes contratantes, consoante se viu em Genebra, a par da convenção unificadora do direito material, a convenção uniformizadora de regras para solução dos conflitos nos pontos de divergência.

Aliás, menos difícil se vem apresentando a tarefa de harmonizar as normas de conflito, em múltiplas ocasiões. Como exemplo de maior valia aí está em vigor o Código de Direito Internacional Privado (Código Bustamante), votado em 1928 pela $6 .^{\text {a }}$ Conferência 
Internacional Americana, realizada em Havana e ratificado por 15 países americanos, abrangendo o direito civil, o direito comercial, o direito penal e o direito processual, através de 437 artigos. Também as Conferências de Haia, principalmente na sua fase mais produtiva, de 1902 a 1905, aprovaram várias convenções uniformizadoras de normas de conflito, como as relativas a casamento, separação de corpos, divórcio e tutela de menores.

Raoul de la Grasserie encara como primordial a etapa - que êle chama provisória - da uniformização das normas de conflito, como se viu em Havana e em Haia no período indicado, para chegarse mais tarde à unificação definitiva do direito comercial, do civil, do administrativo e até do direito político.

Organismo internacionais de função periódica, como a Associação Internacional de Advogados ("International Bar Association"), a Conferência Inter-americana de Advogados, e o respeitável Instituto de Direito Internacional, fundado em Gand em 1873, colimam objetivos unificadores, graças à contribuição de juristas de todos os países. E é de mencionar, pela sua atuação mais recente, o Congresso Hispano-Luso-Americano de Direito Internacional, reunido em São Paulo em 1953.

$\mathrm{E}$ nesse esfôrço uniformizador das normas de conflito, são dig- nos de menção o Congresso de Lima de 1878, de alta importância histórica, por haver sido o primeiro no mundo para fixação de regras de direito internacional privado, dêle resultando um tratado em sessenta artigos, e o Congresso de Montevidéu de 1889, do qual o Brasil participou, dêle resultando a assinatura de oito tratados, em vários ramos do direito.

A contribuição doutrinária individual merece também ser lembrada, destacando-se, no Brasil, a memória "Unidade do direito", apresentada em 1900 por João Monteiro, eminente professor de processo civil da Faculdade de Direito de São Paulo, ao Congresso Jurídico Americano.

- Justificado assim o objetivo da presente dissertação, na conformidade do tema enunciado no seu título, fica sugerida a seguinte conclusão: Entre os meios práticos para melhorar os laços da fraternidade universal e, em conseqüência, poder a humanidade viver permanentemente na desejável paz social, deve ser sempre incentivada e promovida, o quanto possível, a unificação do direito, seja, como finalidade mais imediata e de efeito temporário, através da harmonização das normas de conflito nas legislações dos diferentes países, seja, como objetivo principal, através da uniformização definitiva das leis em geral, notadamente as de ordem privada. 